\title{
TINJAUAN ARCA MEGALITIK TINGGIHARI DAN SEKITARNYA
}

\section{Oleh Haris Sukendar}

\section{PENDAHULUAN}

a). Umum.

Situs megalitik Tinggihari terletak di Kabupaten Lahat (Sumatera Selatan). Daerah ini biasa disebut dengan dataran tinggi Pasemah. Peninggalan tradisi megalitik Tinggihari khususnya dan Pasemah pada umumnya sudah terkenal sejak puluhan tahun yang lalu. Para arkeolog Belanda banyak menulis tentang peninggalan ini, antara lain Tombrink (1827).Ulmann (1850), Westenenk (1921), Van der Hoop (1932), dan lainlain. Walaupun demikian problema tentang peninggalan ini tetap masih belum terpecahkan dan perdebatan-perdebatan terjadi tanpa berkesudahan. Untuk pengungkapan latar belakang peninggalan ini masih perlu dilakukan penelitian sistematis, baik survei maupun ekskavasi. Dengan demikian data artefaktual maupun non artefaktual secara horisontal maupun vertikal dapat terekam, sebagai bahan pengungkapan. Daerah Pasemah saat ini menjadi lebih terkenal, karena adanya rencana pemugaran situs Tinggihari sebagai taman purbakala (archaeological-park) (Sukendar 1984).

Setelah para sarjana Belanda menggeluti peninggalan megalitik di sana, titik-titik terang tentang latar belakang serta aspek-aspek susial lainnya telah banyak yang diketahui. Namun dalam hal ini peninggalan-peninggalan bentuk arca megalit masih perlu diteliti secara tersendiri, untuk menjawab berbagai gejala arkeologis yang melatar belakangi arca megalitik tersebut. Berbagai problema yang muncul antara lain adalah :

Latar: belakang munculnya arca-arca megalitik Pasemah yang bersifat dinamis (strongly dynamic agitated style).

- Latar belakang arca megalit dalam bentuk tokoh manusia maupun binatang (harimau, babi hutan, dan lain-lain).

Apakah telah terjadi perubahan tentang prinsip dasar pembuatan arca megalitik yang biasanya berorientasi pada pemujaan arwah menjadi simbol atau lambang.

- Apakah arca yang digambarkan oleh Van Heekeren selalu naik binatang berkaitan dengan kepercayaan bahwa binatang tersebut merupakan kendaraan arwah nenek moyang.

Problema-problema itulah yang menarik bagi penulis untuk mengamati masalah-masalah tersebut.

\section{b). Situasi dan kondisi}

Daerah Tinggihari khususnya dan Pasemah pada umumnya terdiri dari bukit-bukit dengan hutan luas yang menutupi sebagian besar daerah ini, yaitu di kaki bukit Barisan. Pasemah mempunyai ketinggian rata-rata 
antara $750 \mathrm{~m}-1000 \mathrm{~m}$ di atas permukaan air laut. Curah hujan mencapai $1000-3000 \mathrm{~mm}$ per tahun. Tanah pegunungan ini mempunyai kontur yang bervariasi tingginya. Daerah-daerah tersebut teriris oleh kelok-liku sungai Lematang, di mana banyak terdapat batu-batu besar. Pada sungai Lematang inilah nenek moyang pendukung tradisi megalitik diperkirakan mengambil bahan untuk digunakan sebagai sarana tradisi megalitik. Daerah Tinggihari sendiri mempunyai posisi geografis antara $3^{\circ} .50^{\prime}-4^{\circ} 25^{\prime}$ Lintang Selatan dan $103^{\circ} 70^{\prime}$ Bujur Timur. Situs Tinggihari terletak dipinggir jalan besar antara Pulau Pinang - Tinggihari, sekitar $4 \mathrm{Km}$. dari jalan besar yang menghubungkan Lahat - Bengkulu.

\section{c). Penelitian terdahulu.}

Terbitan tertua yang menguraikan tentang peninggalan megalitik di Pasemah adalah artikel Ulmann. Dalam artikel tersebut diuraikan tentang perkiraan adanya pengaruh Hindu pada peninggalan megalitik di Pasemah. Pandangan Ulmann ini didasarkan pada pahatan-pahatan batu besar yang berhasil ditemukan di dataran tinggi Pasemah. Artikel Ulmann tersebut terbit dengan judul "Hindoebelden in de binnenlanden van Palembang" (Ulmann 1850). Perkiraan adanya pengaruh Hindu pada peninggalan megalitik Pasemah itu semakin kuat. Pada tahun 1872 Tombrink berhasil menyusun suatu ulasan tentang peninggalan-peninggalan batu besar di Pasemah yang berakhir pada kesimpulan yang sama dengan pendapat Ulmann. Tombrink memberikan judul karangannya dengan "Hindoe Monumenten in de bovenlanden van Palembang, als van geschiedkundig onderzoek", dimuat dalam TBG vol XIX, 1871, 1 - 45.

Pada kongres di Surakarta tahun 1919, kemungkinan adanya pengaruh Hindu terhadap peninggalan megalitik Pasemah, ditinjau.lebih detil lagi oleh Westenenk dalam De Hindoe-Javanen in Midden-en Sumatra. Sejak kertas kerjanya itu tersebar luas, percaturan tentang megalitik Pasemah agak terhenti.

Baru pada tahun 1932 daerah Pasemah mulai banyak lagi dibicarakan orang. Terbitan-terbitan tentang Pasemah tidak hanya muncul sebagai artikel-artikel singkat di majalah, tetapi berupa sebuah buku pegangan yang merupakan sebuah disertasi yang terbit dengan 191 halaman, 226 foto, dan 17 peta atas jerih payah Van der Hoop, "Megalithische Oudhe den in zuid Sumatra" (Van der Hoop 1932), akhirnya sangat terkenal dan menarik ahli-ahli purbakala. Karena pentingnya buku tersebut bagi ilmu pengetahuan, maka William Sherlaw menterjemahkan di sertasi Van der Hoop ke dalam bahasa Inggris. Karangan Van der Hoop ini memberi sumbangan besar dalam studi megalitik di Indonesia. Bersama-sama dengan disertasi Van der Hoop muncul pula artikel De Bie dalam TBG yang berisi tentang hasil ekskavasi kubur batu di Tanjung Ara. Sejak Van der Hoop berhasil menerbitkan "Megalithische Oudheden in Zuid-Sumatra", maka perdebatan tentang megalitik Pasemah yang mengatakan adanya pengaruh Hindu di satu pihak dan megalitik di lain pihak ber- 
akhir. Peristiwa ini ditandai dengan terbitan tahun 1936 oleh Schuler yang secara terang-terangan menyebut peninggalan di Sumatra Selatan sebagai peninggalan megalitik (Schuler 1936).

Tokoh-tokoh yang pernah mengadakan penelitian-penelitian di Pasemah setelah kemerdekaan antara lain Funke dan Collin dari Barkely University yang datang sekitar tahun 1976, serta ahli-ahli dari Jepang, tetapi sampai sekarang tulisan-tulisan mereka tak kunjung tiba.

\section{DESKRIPSI TEMUAN}

\section{a). Arah hadap.}

Arca megalitik Tinggihari mempunyai arah hadap yang berbeda-beda. Arah hadap arca-arca di sini kelihatannya tidak mempunyai arti tertentu, hal ini tampak dengan jelas adanya arah yang berbeda-beda. Arah hadap arca tersebut adalah sebagai berikut :

Arca megalitik Tinggihari 1

(Amt 1) menghadap ke timur

Amt 2 menghadap ke barat laut

Amt 3 menghadap ke tenggara

Amt 4 menghadap ke tenggara

Amt 5 menghadap ke barat laut

Amt 6 tidak diketahui arah hadapnya, karena tidak in situ.

Amt 7 menghadap ke arah barat

Amt 8 menghadap ke arah barat laut

Amt 9 menghadap ke arah timur.

Dengan adanya arah hadap arca megalitik Tinggihari yang berbeda-beda, maka apa yang diinformasikan Van der Hoop bahwa benda-benda megalit Pasemah mengarah ke gunung Dempo (Van der Hoop 1932) perlu dikaji kembali. Memang arah hadap suatu megalit kebanyakan dikaitkan dengan tujuan-tujuan tertentu. Hal ini seperti apa yang dikatakan oleh Perry tentang arca-arca megalitik di daerah Sulawesi Tengah (Perry 1938) dan peninggalan megalitik di Bondowoso yang dikatakan menghadap ke gunung Raung (Van Heekeren 1931).

\section{b). Bentuk.}

Arca-arca megalitik Tinggihari biasanya digambarkan serba gemuk dan tambun, baik kaki, badan perut, tangan, leher, dan lain-lain. Badan arca kebanyakan dalam posisi membungkuk dengan kepala menghadap lurus ke depan atau agak tengadah. Kepala biasanya memakai tutup berbentuk bulat. dan mata biasanya digambarkan melotot. Anggota badan yang lain digambarkan secara sempurna. Arca biasanya digambarkan berjongkok dengan kaki ditekuk ke belakang, sedang tangan memegang paha atau binatang gajah atau kerbau. Kalung biasanya digambarkan seperti untaian manik-manik sedang tangan atau kaki kebanyakan di- 
gambarkan memakai gelang yang berdasarkan bentuk melukiskan gelang perunggu. Gelang tangan digambarkan seperti lepengan perunggu. sedang gelang kakinya dibuat dari perunggu berbentuk bulat. Nekara perunggu kadang-kadang dipahatkan pada bagian belakang (punggung). Berdasarkan pengamatan yang dilakukan penulis ternyata arca binatang yang dipahatkan bersaina-sama dengan tokoh manusia, tidak dikendarai seperti yang dikatakan oleh Van der Hoop, tetapi tampaknya hanya dibelai atau dipeluk. Penggambaran binatang yang dipahatkan ber-sama2 tokoh manusia ini bukan tidak mungkin mempuryai tujuan tertentu. Arca megalitik Tïnggihari ada yang digambarkan memakai baju tipis yang oleh Van der Hoop biasa disebut dengan tunik (ponco) (Van der Hoop 1932). Selain bentuk-bentuk tokoh manusia, arca megalitik Tinggihari dan sekitarnya digambarkan dengan babi hutan, harimau dan gajah. Bentuk pahatan arca yang kaya dan lengkap ini oleh Von Heine Geldern dan Van Heekeren dikatakan sebagai arca yang dinamis. Untuk memberikan gambaran yang jelas terhadap Ideskripsi arca megalitik di Tinggihari baiklah disini diuraikan tanda-tanda dan ciri khusus beberapa arca megalitik Tinggihari sebagai contoh.

\section{a). Arca megalitik Tinggihari 1 .}

Arca megalitik Ting gihari digambarkan serba besar dan tambun, dan kelihatan kaku serta bungkuk. Tidak jauh dari arca ini ditemukan sebuah batu datar (batu papan) yang berukuran $125 \mathrm{~cm}$ (panjang), $75 \mathrm{~cm}$ (lebar) dan $25 \mathrm{~cm}$ (tebal). Seperti biasa arca ini digambarkan dalam posisi berjongkok. Leher dari arca ini digambarkan sangat besar dan kelihatan sangat membungkuk.

Bagian kepala arca telah hilang dan kelihatan memakai pakaian tipis yang dapat diketahui melalui pengamatan dari bagian leher dan dadanya. Pada bagian leher terdapat untaian manik-manik berbentuk heksagonal. Kedua tangannya memakai gelang, dan berdasarkan bentuknya menggambarkan gelang dari lempengan perunggu. Pada kedua kakinya terdapat 5 buah gelang kaki berbentuk bulat yang kemungkinan juga menggambarkan gelang kaki dari perunggu. Kedua tangan arca tokoh manusia ini digambarkan memegang makhluk yang tidak jelas bentuknya, karena telah pecah dan kepalanya belah. Tetapi dilihat dari bentuk tangan dan bahu kedua tokoh yang dipegang tersebut mungkin merupakan tokoh manusia yang digambarkan lebih kecil.

Arca megalitik Tinggihari ini berukuran tinggi $135 \mathrm{~cm}$, lebar bahu 102 $\mathrm{cm}$ dan lebar pinggang $80 \mathrm{~cm}$.

\section{b). Arca megalitik Tinggihari 2}

Arca ini berupa arca babi hutan yang merupakan arca megalitik yang ditemukan setelah adanya penelitian gabungan dari Puslit Arkenas. Ditlinbinjarah, Kanwil Depdikbud Sumatera Selatan, Kandepdikbud Kabupaten Lahat serta Kantor Depdikbud kecamatan Pulau Pinang, yang dilakukan pada tahun 1983. Penelitian gabungan ini merupakan suatu studi 
kelayakan bagi daerah Lahat. Van der Hoop mengatakan bahwa arca babi hutan ini merupakan "arca yang belum selesai" (unfinished statue), dan tidak menyebutkan binatang apa yang diarcakan. Arca itu berukuran panjang $325 \mathrm{~cm}$, tinggi $95 \mathrm{~cm}$ terletak sekitar $130 \mathrm{~m}$ sebelah selatan menhir utama. Babi hutan ini ditemukan dalam posisi menghadap ke utara dan ekor ada di bagian selatan. Berdasarkan pengamatan terhadap posisi babi hutan ini maka dapat diketahui bahwa babi yang digambarkan dalam arca ini sudah dalam keadaan mati. Namun demikian masih perlu penelitian yang lebih seksama lagi.

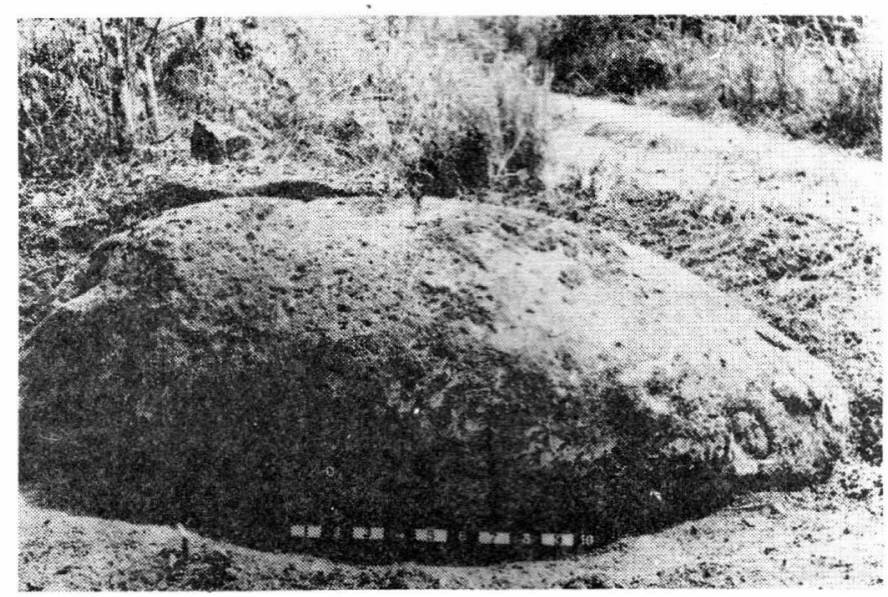

Arca megalitik Tinggihari 2

\section{c). Arca megalitik Tinggihari 3 .}

Arca ini terletak $1 \mathrm{~m}$ di sebelah kanan jalan Pulau Pinang - Tinggihari dan menghadap ke arah barat laut, seperti arca Tinggihari 4 . Tidak jauh dari arca tersebut sekitar $13 \mathrm{~m}$ di sebelah barat laut yaitu di kebon kopi, terdapat lumpang batu (stone-mortar) dengan 3 buah lubang.

Arca ini digambarkan dalam posisi duduk dengan kaki tertekuk ke belakang, menggambarkan seorang tokoh manusia yang sedang menyusui anaknya. Anak ini digendong di sebelah kanan. Buah dada sebelah kiri dari arca perempuan ini kelihatan dengan jelas dan menonjol. Tidak seper. ti arca-arca yang lain maka arca ini tidak memakai tutup kepala. Tangan dalam posisi lurus ke bawah dan kelihatannya memegang telapak kaki. Pada pergelangan tangannya terdapat gelang yang kelihatannya menggambarkan gelang perunggu, sedang pada bagian lehernya terdapat untaian manik-manik berbentuk heksagonal. Kepala arca tampak menengadah sedang badannya kelihatan bungkuk. 


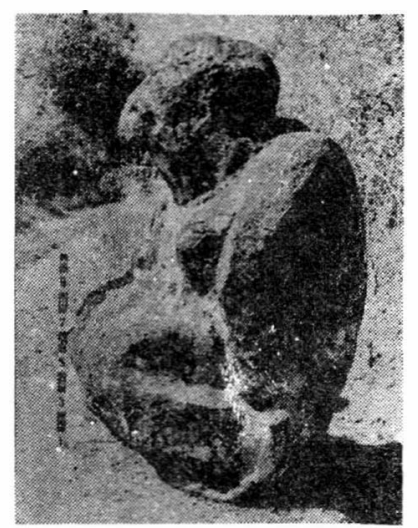

Arca megalitik Tinggihari 3.

\section{d). Arca megalitik Tinggihari 4.}

Arca ini terletak $1,5 \mathrm{~m}$ di sebelah kanan jalan yang menghubungkan Pulau Pinang - Tinggihari dan menghadap ke arah tenggara. Arca yang menggambarkan tokoh pahlawan tersebut digambarkan memegang/membelai gajah dan kerbau. Arca ini digambarkan dalam keadaan berjongkok dan memakai tutup kepala.. Pada pergelangan tangan terdapat gelang yang berdasarkan bentuknya menggambarkan gelang perunggu. Daun telinga tampak jelas di luar tutup kepala. Seperti arca megalitik Tinggihari lainnya arca ini digambarkan membungkuk. Oleh penduduk setempat arca ini disebut dengan "arca imam". Ukuran arca megalitik ini adalah tinggi $240 \mathrm{~cm}$ dan lebar bahu $125 \mathrm{~cm}$.

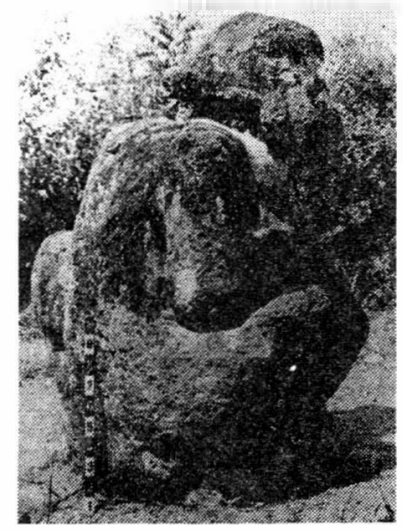

Arca megalitik Tinggihari 4. 


\section{e). Arca megalitik Tinggihari 5.}

Arca ini merupakan temuan penting dari situs Tinggihari bagian selatan Arca terletak di pinggir jalan besar Pulau Pinang-Tinggihari sekitar $4 \mathrm{~m}$ dari jalan besar. Arca megalitik ini berorientasi kearah barat laut. Keanehan dari arca megalitik ini adalah adanya 2 buah tonjolan yang terdapat di sebelah kanan maupun kiri bagian atas kepala. Arca ini menggambarkan tokoh manusia yang gagah perkasa menggendong seekor gajah dan disamping itu di badan sebelah kanan arca terlihat pahatan yang menggambarkan seekor buaya. Arca megalit ini digambarkan memakai tutup kepala berbentuk bulat. Pada bagian dahinya terdapat tonjolan yang menggambarkan tali pengikat kepala (rambut). Arca digambarkan memakai baju dan memakai gelang yang berdasarkan bentuknya dibuat dari perunggu. Pada pergelangan tangannya terdapat gelang yang berdasarkan atas bentuk pahatan menggambarkan gelang dari lempengan perunggu. Demikian pula pada pergelanan kakinya terdapat gelang berjumlah 9 buah.

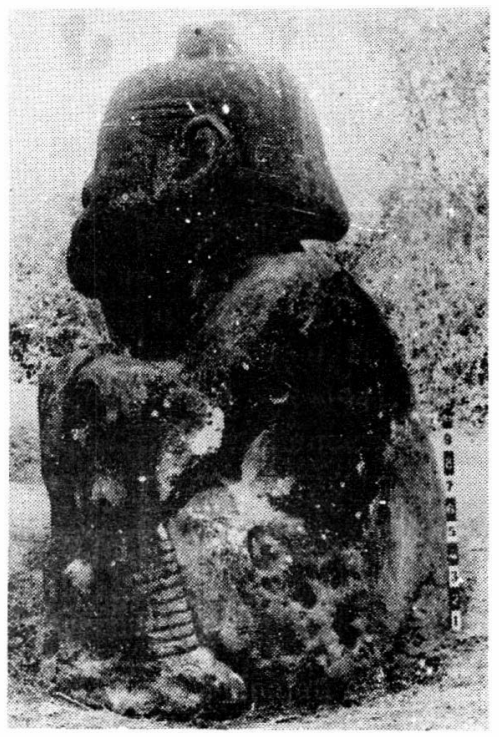

Arca Megalitik Tinggihari 5. (dari samping).

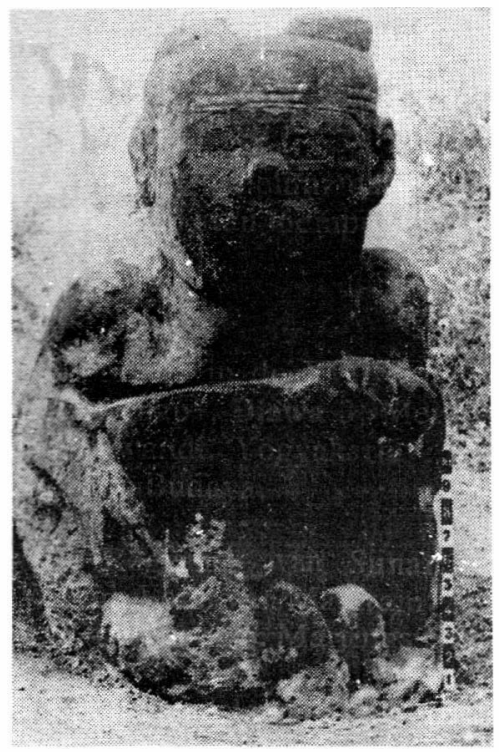

Arca Megalitik Tinggihari 6. (dari depan). 


\section{P E M B A H A S A N}

Peninggalan arca-arca megalitik Tinggihari dan sekitarnya menunjukkan adanya peningkatan dalam keahlian teknik pahat batuan. Bentukbentul arca sangat dinamis walaupun penggambaran arca itu sendiri mempunyai bentuk-bentuk yang serba besar, tambun dan kaku. Teknik pemahatan batu kelihatan mempunyai nilai yang tinggi yang menunjukkan "Local genius" daerah Pasemah dalam pemahatan batu. Puluhan situs megalitik yang ditemukan, seperti di Sumatera Utara, Nias, Lampung, Jawa Barat, Sulawesi dan lain-lain, walaupun merupakan peninggalan tradisi megalitik yang muncul pada masa yang hampir bersamaan dengan megalitik Pasemah, tetapi arca Pasemah menunjukkan gayanya yang tersendiri. Kekhususan peninggalan bentuk arca di Pasemah inilah yang justru memberikan da ya tarik dari para peneliti.

Peninggalan arca-arca megalitik di daerah Gunung Kidul, Jawa Barat, Sulawesi Tengah serta tempat-tempat lain di sektor Indonesia bagian timur dapat dikatakan merupakan peninggalan yang bersifat statis. Hasil pemahatan arca megalitik pada situs-situs megalitik tersebut diatas-

biasanya kasar dan bentuknya sangat sederhana. Arca-arcanya berbentuk bulat panjang, di bagian puncaknya digambarkan muka manusia (biasa disebut dengan arca menhir). Anggota badan seperti tangan dan muka biasanya digambarkan sangat kasar dan sederhana.

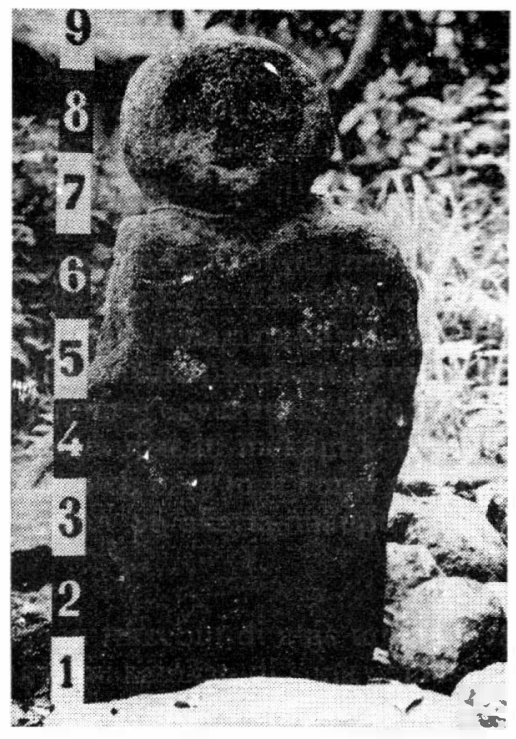

Arca menhir dari Pandegelang

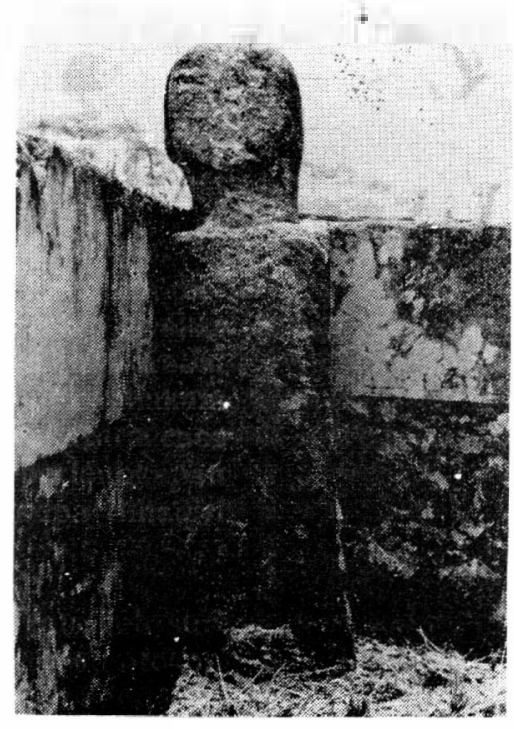

Arca menhir dari Gunung Kidul 
Bcrdasarkan atas perbandingan antara arca megalit Pasemah dan arca dari situs-situs yang lain maka dapat diketahui bahwa arca di daerah Pasemah ini mempunyai teknologi maju. Kreatifitas pemahatnya sangat tinggi, dengan hasil pahatan yang bervariasi, Arca megalitik dalam bentuk tokoh manusia (human figure) sebagian besar dipahatkan dalam posisi berjongkok, kadang-kadang tangan di atas lutut, memegang betis dan kadang-kadang memegang binatang seperti gajah, harimau atau kerbau.

Tentang arca megalitik Pasemah telah ditinjau oleh Van Heekeren, Von Heine Geldern, Van der Hoop dan R.P. Soejono (Van Heekeren 1958, Van der Hoop 1932, R.P. Soejono 1982). Di dalam The Bronze-Iron Age of Indonesia Van Heekeren telah menyitir apa yang dikatakan oleh Von Heine Geldern tentang arca Pasemah. "The stone statues are among the most interesting features of the maglithic culture of the Pasemah plateau. They are large statues, sculptured in a "strongly dinamic agitated" style (Van Heekeren 1958). Sehubungan dengan tipe-tipe arca Pasemah dan tipe-tipe arca menhir di daerah lain, lebih lanjut R.P. Soejono dalam "On the Megaliths in Indonesia" mengatakan sebagai berikut.

"Stone statues occur in different styles in what is usually determined as static and dinamic. The static style is shown on the so called "menhir statues" and on "the polynesian statues". Menhir statues are carved oblong stone showing the human face sometimes the genitals and arms for instance at Wonosari (Central Java), Besuki and Toraja; polynesian statues are proportionally carved; mostly in sitting or squatting position (R.P. Soejono 1982). Selanjutnya R.P.Soejono mengatakan pula bahwa peninggalan arca megalitik di daerah Pasemah merupakan arca dinamis.

Apa yang dikatakan oleh Von Heine Geldern maupun Van Heekeren yang diikuti pula oleh R.P. Soejono, Teguh Asmar dan penulis sendiri memang beralasan. Alasan Von Heine Geldern untuk memberikan julukan arca dinamis memang cukup kuat. Hal ini didasarkan atas studi perbandingan melalui tipologi arca-arca dari berbagai situs megalitik di Indonesia. Apa yang digambarkan sebagai arca dinamis ditandai dengan bentuk-bentuk pahatan yang hidup dan lebih kaya. Liuk-liuk bentuk badan digambarkan dengan jelas dan nyata meskipun secara keseluruhan kelihatan tambun dan kaku. Arca megalitik yang ditemukan di situs Tinggihari dan sekitarnya tidak lagi berbentuk statis seperti yang ditemukan di Gunung Kidul, Sukasari Sulawesi Tengah dan lain-lain (Perry, 1938, Van der Hoop 1935. Van Hcekeren 1931). Ciri-ciri khusus arca menhir yang ditemukan pada situs-situs megalitik tersebut adalah:

mempunyai tipe statis dengan pahatan-pahatan sederhana dan miskin biasanya berbentuk silinder yang hanya terdiri dari bagian badan dan kepala. scdang bagian kaki tidak ada. 
- anggota badan seperti tangan dan bagian muka (mata, hidung, telinga dan mulut) dipahatkan sangat sederhana bahkan kadang-kading hanya berupa lubang atau garis-garis saja.

bentuk primitif dan kelihatan kaku.

Perry di dalam "Megalithic Finds in Central Celebes" menyebutkan salah satu arca dari peninggalan tradisi megalitik di Sulawesi Tengah sebagai. berikut :

"Almost in the centre of the village the stone images, of men's height, 179 centimetres, stand. As will be seen in figs 52-55 this images is an almost cylindrical block of stone in which a face is carved. Arms, nipples and generative organs are executed in low relief. A neck is but slightl. marked. the face is of usual style, the eyebrows, however, straighter than in most other statues, which have slanting carved eye-brows......" (perry 1938, 99).

Di dalam hal ini Van der Hoop juga berhasil menemukan arca menhir seperti tersebut di atas di dataran tinggi Pasemah yaitu di Muaradua Komering dan Ranau. Rupanya Van der Hoop masih berhasil menemukan arca menhir di antara sejumlah arca megalit dinamis di Pasemah. Adapun tanda-tanda arca menhir yang merupakan temuan langka di dataran Pasemah ini dituliskan oleh Van der Hoop sebagai berikut :

"Both consists, of an oblong stone, on the top of which a head is given, roughly represented in "relief" whilst on the front surface; the thin shapeless limbs are awkwardly sculptured out in the same style" (van der Hoop, 1932).

Arca megalit dengan bentuk-bentuk seperti ini oleh penulis disebut sebagai arca menhir (menhir statues). Hal ini didasarkan atas bentuk arca itu sendiri yang merupakan pencampuran antara arca dan menhir (Sukendar 1971). Jadi arca menhir merupakan transisi antara menhir dan arca megalit. Di dalam kenyataan arca-arca menhir yang ditemukan pada situssitus kubur dan upacara seperti di Nias, Lampung, Jawa Barat, Gunung Kidul (Jateng), Bondowoso (Jatim) dan Sulawesi serta NTT mempunyai bentuk-bentuk yang sangat sederhana, baik bentuk susunan anggota badan, maupun pemahatannya. Pemahatan dalam bentuk yang sederhana ini kemungkinan mempunyai latar belakang tersendiri. Dalam hubungannya dengan bentuk-bentuk yang primitif dan kurang lengkap dari arcaarca menhir di atas, penulis sangat menyetujui apa yang dikatakan oleh Sumijati As bahwa seni prasejarah dalam penggambaran obyeknya lebih menonjolkan arti simbolisnya dari pada ketepatan proporsi anatomisnya (Sumijati As, 1984). Perlu diketahui bahwa arca menhir sebagian besar ditenukan pada situs-situs kubur (burial sites). Arca menhir yang berhubungan dengan kubur adalah : 
Arca menhir yang berhubungan dengan kubur adalah:

- Arca menhir di Liwa (Lampung Utara ditemukan pada kubur berundak).

Arca menhir Gunung Kidul ditemukan pada kubur peti-batu (stone cist).

Arca menhir di Bondowoso ditemukan pada situs kubur phandusa. Arca menhir di Sumba ditemukan pada kubur dolmen.

- Arca menhir di Sulawesi Tengah ditemukan pada kubur kalamba (stone-vats).

(Sukendar 1977, Van der Hoop 1935, Van Heekeren 1931. Perry, 1938) Arca-arca ini semuanya tergolong dalam arca nenek moyang yang biasanya dibuat sebagai personifikasi dari arwah nenek moyang. Penggambaran bentuk sederhana ini mempunyai maksud-maksud tertentu yang berkaitan dengan kehidupan setelah mati.

Bentuk-bentuk yang sederhana (primitif) ini kemungkinan dianggap merupakan bentuk yang paling cocok, khususnya dalam kaitan dengan gaib atau alam setelah mati.

Berdasarkan pengamatan yang dilakukan oleh penulis pada arca-arca megalitik Pasemah, khususnya arca-arca di Tinggihari dan sekitarnya maka dapat diketahui tanda-tanda arca megalitik Pasemah sebagai berikut :

- Bentuk badan dipahatkan secara lengkap

- Pahatan-pahatannya lebih kaya dan sudah maju dengan bentuk yang dinamis.

Jenis arca megalitik terdiri dari arca-arca yang menggambarkan tokoh manusia dan binatang (gajah, harimau, babi hutan dan kerbau). Teknologi pemahatan lebih maju dan hasil pahatan yang lebih rumit dan bervariasi

Tentang bentuk-bentuk arca tokoh manusia yang digambarkan bersamasama dengan gajah, van der Hoop mengatakan sebagai berikut :

"The image represents a man riding on an elephant, but the later in propotion to the former has the dimension of the large dog" (Van der Hoop. 1932).

Sehubungan dengan hal tersebut di atas Van Heekeren dalam The Bronze Iron Age of Indonesia juga telah mendiskripsikan arca tokoh manusia yang mengendarai binatang antara lain di Karangindah Pasemah. Tanjungsirih, Tinggihari dan Tebatsibentur.

Di Karangindah (Pasemah) ditemukan arca seorang tokoh pahlawan naik seekor gajah; di Tanjungsirih ditemukan arca seorang tokoh naik kerbau; di Tinggihari di temukan arca tokoh manusia mengendarai seekor kerbau dan di Tebatsibentur ditemukan arca laki-laki mengendari kerbau (Van Heekeren, 1958 : 75). 
Berdasarkan atas uraian Van der Hoop dan Van Heekeren tersebut di atas maka muncul kesimpulan bahwa kendaraan-kendaraan tokoh manusia antara lain kerbau dan gajah.

Di dalam pengamatan penulis, di situs Tinggihari dan sekitarnya memang terdapat arca-arca pahlawan yang digambarkan bersama-sama dengan kerbau, gajah, harimau tetapi tampak dengan jelas bahwa binatang-binatang tersebut tidak dikendarai tetapi justru dibelai. Pahatanpahatan binatang seperti gajah, kerbau, dan harimau selalu dipahatkan di sebelah kanan depan atau kiri tokoh manusia tersebut.

Sehubungan dengan problem tersebut di atas Satyawati Suleiman di dalam REHPA (Rapat Evaluasi Hasil Penelitian Arkeologi) di Cisarua, Bogor telah menekankan bahwa pemahatan binatang seperti gajah tidak harus perlu dihubungkan dengan kendaraan arwah nenek moyang. Berkaitan dengan apa yang dikatakan oleh Satyawati Suleiman tersebut Van der Hoop juga telah menuliskan dan memberikan jawaban secara tidak langsung sebagai berikut. "In connection with the race question, a story we heard during our enquiry in worth mentioning Mr. C. Raupp, of Tanjungtebat often went out elephat-hunting with the Koeboes, who dwell on the Soengai Teras, a tributary of the Soengai Semangoes, in its turn a tributary of the Moesi. He related that these Koeboes regard an elephant as sacred, on the ground that this animal was the riding animal of their ancestors. They killed an elephant only in cases of extreme necessity" . (Van der Hoop 1932, 79).

Untuk pengujian tentang pahatan gajah dalam hubungannya dengan binatang kendaraan arwah nenek moyang pendukung tradisi megalitik, maka perlu dilakukan studi etno arkeologi diberbagai pulau di Indonesia Timur. Hal ini mengingat bahwa banyak terdapat pahatan yang menggambarkan gajah dan binatang-binatang lain yang mungkin masih dapat ditanyakan kepada penduduk setempat tentang maknanya.

Berdasarkan atas hasil wawancara di situs-situs megalitik Sumba Timur ternyata pahatan gajah yang terdapat pada penji-penji (menhir) tidak dikaitkan dengan pengertian gajah sebagai kendaraan arwah nenek moyang. Berdasarkan uraian tersebut di atas penulis sangat setuju dengan apa vang dikatakan Satyawati Suleiman bahwa gajah tidak perlu dikaitkan dengan kendaraan arwah nenek moyang.

Problem munculnya arca megalitik yang terdiri dari berbagai hentuk perlu penjelasan lebih detil, karena munculnya arca megalitik ini berkaitan erat dengan prinsip dasar pendirian suatu megalith. Masih terlalu sulit untuk menentukan tentang latar belakang arca megalitik yang dibuat Jalam bentuk manusia, babi hutan, gajah, harimau, menjangan dan lainlain. Di dalam artikel "Prinsip dasar pendirian megalit Nias" yang dibacakan di REHPA 1984 penulis telah menyoroti herbagai latar belakang pendirian megalit antara lain : pemujaan arwah nenek moyang. adanya kepercayaan bahwa binatang merupakan kendaraan arwah, hubungan 
yang sangat erat antara binatang dengan kehidupan masyarakat megalit, binatang dianggap dapat melindungi masyarakat, dan sifat-sifat raja yang dilambangkan sebagai sifat binatang.

Arca-arca megalitik yang menggambarkan binatang di situs megalitik Pasemah mengingatkan kembali kepada arca-arca kepala binatang dari situs megalitik Terjan. Dari Hasil ekskavasi pada situs ini ternyata arcaarca kepala binatang yang digambarkan berkaitan dengan upacara penguburan. Kemungkinan arca tersebut dimaksudkan sebagai penjaga atau pelindung si mati dalam kehidupan kemudian di alam arwah. Hal ini tentunya berbeda dengan arca binatang dari Pasemah. Bukan tidak mungkin bahwa arca-arca ini merupakan sarana pemujaan agar binatang-binatang buas tersebut tidak mengganggu kehidupan masyarakat dan agar antara masyarakat dan binatang dapat hidup berdampingan. Van der Hoop telah menemukan arca tokoh manusia yang sedang bertempur melawan gajah (Van der Hoop 1932). Dalam hal ini gajah rupanya merupakan binatang yang cukup berbahaya selain harimau, ular, buaya dan lain-lain. Dari pengamatan arca megalit Pasemah dapat diketahui adanya perkembangan-perkembangan bentuk arca megalitik Pasemah sebagai berikut :

Pada bagian kepala tampak adanya pahatan tutup kepala yang berbentuk bulat, yang kelihatannya berdasarkan bentuknya dibuat dari logam. Perkembangan pada pahatan di bagian badan ialah munculnya pakaian tipis yang oleh Van der Hoop disebut tunik. Gelang kaki dan gelang tangan digambarkan dengan pahatan yang sempurna. Nekara perunggu kadang-kadang dipahatkan sebagai pelengkap pada bagian punggung tokoh manusia. Dengan adanya pahatan yang cukup kaya, proporsi anatomi yang lengkap dan dengan bentuk arca yang besar, tambun dan kaku, maka tidak mengherankan jika Van Heekeren menyebutkan sebagai "Strongly dynamic agitated" style.

\section{KESIMPULAN}

\section{a). Munculnya arca megalitik Pasemah yang dinamis.}

Arca megalitik Pasemah pada prinsipnya bukan merupakan arca untuk keperluan sebagai tanda penguburan atau penggambaran dari orang yang dikuburkan. Arca ini ditemukan tidak pada tempat penguburan, tetapi tampaknya didirikan pada situs pemukiman di mana ditemukan umpakumpak batu bekas bangunan, lumpang batu, batu datar, menhir serta pecahan-pecahan gerabah. Munculnya arca yang dinamis dan megah ("strongly dynamic agitated" style) mungkin disebabkan karena arcaarca ini menggambarkan tokoh-tokoh manusia yang berkuasa pada waktu itu. Sehingga dengan demikian bukan tidak mungkin si pemahat membuat arca tersebut dengan lebih menonjolkan segi kesempurnaan bentuk maupun keagungannya dari pada arca menhir yang ditemukan pada situssitus penguburan. Arca Pasemah mempunyai bentuk badan yang serba hesar serta tambun dengan pakaian atau perlengkapan yang cukup. 


\section{b). Latar belakiang munculnya tokoh manusia dan binatang.}

Penggambaran tokoh-tokoh binatang seperti yang dijumpai di Pasemah yaitu ular, gajah, kerbau, harimau, rusa dan babi hutan memang sangat jarang terjadi pada situs-situs megalitik. Arca binatang ini dibuat oleh pendukung tradisi megalitik tidak hanya sebagai binatang kendaraan arwah, tetapi kemungkinan mempunyai arti yang lebih luas antara lain berkaitan dengan harapan mereka agar binatang tersebut tidak mengganggu, agar mereka dapat hidup berdampingan dengan tentram, Di samping itu dengan adanya arca babi hutan yang seolah-olah menggambarkan babi yang relah mati dan juga dengan ditemukannya arca rusa mengingatkan kepada adat perburuan.

Pembuatan arca-arca tersebut kemungkinan berkaitan dengan harapan agar dalam berburu mereka mendapat hasil yang lebih banyak, seperti arti gambar-gambar babi hutan dari gua-gua di Sulawesi Selatan.

\section{c). Perubahan prinsip dasar pada pembuatan arca megalit.}

Pendirian megalit biasanya selalu berkaitan dengan pemujaan atau penguburan. Arca-arca megalitik Pasemah khususnya yang berupa arca manisia tampaknya cenderung melukiskan kepala-kepala adat atau penguasa dan arca tersebut merupakan lambang atau simbol mereka. Demikian pula arca-arca binatang kemungkian juga berkaitan dengan simbol atau lambang, bukan berkaiatan untuk kepentingan penguburan atau pemujaan arwah semata-mata.

\section{d). Apakah arca binatang selalu menggambarkan kendaraan arwah.}

Apa yang dikatakan oleh peneliti terdahulu bahwa arca tokoh-tokoh manusia di Pasemah selalu naik gajah atau kerbau masih menjadi pertanyaan. Pengamatan yang dilakukan pada situs megalitik Tinggihari ternyata memberikan petunjuk bahwa binatang-binatang tersebut tidak sclalu dikendarai. Penggambaran binatang selain menggambarkan binatang kendaraan arwah mungkin juga berkaitan dengan maksud-maksud lain sebagai simbol atau lambang.

\section{Ke pus t a k a a n}

Asmar. Teguh "Megalitik di Indonesia, ciri dan problimnya"

1975 Bulletin YAPERNA, Yayasan Perpustakaan Nasional Jakarta. No. 7 Tahun - 11 .Juni.

Bic, C.W.P. de "Verslag van de uitgraving der stecnen kamers in de 1932 de doesoen Tandjoeng Ara, Pasemah-Hoogulikte" Tijdscrift Bataviaasch Genootschap, vol L.XXII. pp. $626-6.35$. 
Callenfels. P.V. Stein, Pedoman Singkat Koleksi Prasejarah Museum 1961 Pusat Lembaga Kebudayaan Indonesia, Revisi oleh Drs. R.P. Soejono, Cetakan ke 4.

Harun Kadir Aspek Megalitik di Toraja Sulawesi Selatan, makalah untuk 1977 Pertemuan Ilmiah Arkeologi I di Cibulan.

Heekeren, H.R. van, "Megalithische overblijfselen bij Bondowoso", Djawa 1931

1958 Koninklijk Instituut voor Taal, Land-en Volkenkunde, 's-Gravenhage : Marinus Nijhoff.

Penghidupan dalam zaman Prasejarah di Indonesia, 1960 terjemahan Moh. Amir Sutaarga, Cetakan ke-2, Jakarta, Soeroengan.

Heine Geldern, R: Von, "Prehistoric Research in the Netherlands Indies", 1945 Science and Scientists in the Netherlands Indies, dalam Peter Honig dan Frans Verdoorn.

Hoop, A.N.J. Th.a. Th. van der, Megalithic Remains in South Sumatra, 1932 terjemahan William Shirlaw, Zuthpen : W.J. Thieme.

1935

"Steenkistgraven in Goenoeng Kidoel" TBG 75.

1938 Indie, deel l, Amsterdam. Joost van den Vondel.

Loofs. H.H.E. Elements of the Megalithic Complex in Southeast Asia, 1967 Canberra : Australian National University Press.

Munanjar Widiyatmika dkk, Adat istiadat Daerah Nusa Tenggara Timur, 1977/1978 Jakarta. Departemen Pendidikan dan Kebudayaan, Pusat Penelitian Sejarah dan Budaya Proyek Peneltian dan Pencatatan Kebudayaan Daerah.

Perry, W.J. The Megalithic Culture in Indonesia, Manchester. 1918

Rokhus Duc Awe dan Budi Santosa Aziz. sporan Penelitian Kepurbakala1978 an di Nusa Tenggara Timur, in press. 
Schuler C.W. "Meghalithische oudheden in de Palembangsche boven-

1936 landen en Overheidszorg, TBG vol LXXVI, 396-397

Socjono, R.P. Sistem-sistem penguburan pada akhir masa Prasejarah 1977 di Bahi, Jakarta (desertasi untuk mencapai gelar Doktor pada Universitas Indonesia).

1981

\section{Sejarah Nasional Indonesia I.}

1982 Asia, Hanyang University Press.

Sukendar, Haris Penyelidikan megalitik di daerah Wonosari Gunung Kidul

1971 skripsi sarjana, Fak. Sastra dan Kebudayaan Universitas Gajah Mada.

Tinjauan tentang peninggalan tradisi megalitik di daerah

1977 Sulawesi Tengah. Makalah untuk Pertemuan Ilmiah Arkeologi I.

Monografi Peninggalan tradisi megalitik di daerah Nias, In Press.

Sumijati As. "Lukisan Manusia di Pulau Lomblen (Tambahan Data Hasil

1984 Seni Bercorak Prasejarah)," Dalam Berkala Arkeologi $v(1)$.

Tombrink, E.P. "Hindoe-Monumenten in de bovenlanden van Palem1872 bang, als bron van geschiedkundig onderzoek", TBG, vol XIX, 1 - 45 .

Westenenk, L.C. "De Hindoe-Javanen in Midden en Zuid Sumatra",

1919 Handelingen van het Eerste Congres voor de Taal, Land-en Volkenkunde van Java, Solo, 1 - 46. 